\title{
Minimum Residual Flows for Catchments in the Czech Republic
}

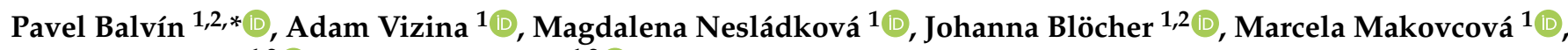 \\ Vojtěch Moravec ${ }^{1,2}\left(\mathbb{D}\right.$ and Martin Hanel ${ }^{1,2} \mathbb{D}$ \\ 1 T. G. Masaryk Water Research Institute, Podbabská 2582/30, 16000 Praha, Czech Republic; \\ adam.vizina@vuv.cz (A.V.); magdalena.nesladkova@vuv.cz (M.N.); johanna.blocher@vuv.cz (J.B.); \\ marcela.makovcova@vuv.cz (M.M.); vojtech.moravec@vuv.cz (V.M.); hanel@fzp.czu.cz (M.H.) \\ 2 Faculty of Environmental Sciences, Czech University of Life Sciences Prague, Kamýcká 129, \\ 16500 Praha, Czech Republic \\ * Correspondence: pavel.balvin@vuv.cz
}

Citation: Balvín, P.; Vizina, A.;

Nesládková, M.; Blöcher, J.;

Makovcová, M.; Moravec, V.;

Hanel, M. Minimum Residual Flows

for Catchments in the Czech Republic.

Water 2021, 13, 689. https://doi.org/

10.3390/w13050689

Academic Editor: David Dunkerley

Received: 22 January 2021

Accepted: 24 February 2021

Published: 3 March 2021

Publisher's Note: MDPI stays neutral with regard to jurisdictional claims in published maps and institutional affiliations.

Copyright: (c) 2021 by the authors. Licensee MDPI, Basel, Switzerland. This article is an open access article distributed under the terms and conditions of the Creative Commons Attribution (CC BY) license (https:/ / creativecommons.org/licenses/by/ $4.0 /)$.
Abstract: The determination of minimum residual flow (MRF) follows diverse methodology in Europe due to differing hydrological conditions, ecosystem requirements, water abstraction requirements, and legislation. Methodologies in individual countries are difficult to compare qualitatively. However, individual approaches can serve as examples for countries undergoing the process of developing new methodologies, either for legislative purposes or to improve environmental standards on watercourses. This is exactly the situation in the Czech Republic which, has been working on the Regulation of the Government of the Czech Republic for ten years, since the amendment to the Water Act in 2010, defines the methods and criteria for determining the MRF on watercourses. T.G. Masaryk Water Research Institute, p.r.i., was commissioned to develop a new methodology to serve as the basis for the wording of aforementioned regulation. The new methodological approach took into account modern trends concerning the preservation of ecological standards, and used standard hydrological characteristics for its calculations. The newly proposed approach is undergoing a complicated approval process as the authors seek to increase the MRF compared to the current approach. The new approach assumes an MRF setting between $Q_{97}$ and $Q_{90}$. It defines four areas within the Czech Republic, by their hydrological and hydrogeological conditions, where the MRF is determined in different ways. This article describes the development of a new methodological approach, including the use the available Czech Hydrometeorological Institute data sets, the proposed regional division for MRF calculations, the determination the MRF below reservoirs, and the current state of the issue.

Keywords: residual flow; environmental flow; new methodology; regionalization; seasonality of MRF

\section{Introduction}

A gradual increase in temperature is observed across the whole European continent [1], which has also affected hydrological regimes including that of the Czech Republic. Especially in recent years, when slightly increasing precipitation totals can no longer compensate for the increasing evapotranspiration due to the temperature increase runoff has decreased. This changing trend exerts more pressure on water management. Furthermore, from the ecological point of view, it is necessary to consider the ecological sustainability of watercourses. Some directives defining the ecological flows already exist (European commission guidance - ecological flows in the implementation of the Water Framework Directive (WFD) [2] and World Meteorological Organization [3]). Within Office for Official Publications of the European Communities [2], there is also a document with several studies conducted in European countries, in which ecological flows for individual basins are addressed [4]. The definition of ecological flow varies from country to country, but the main goal of defining such a flow is to provide enough water in the watercourse to sustain aquatic life and provide sufficient dilution of the cleaned wastewater downstream 
of wastewater treatment plants. The minimum residual flow (MRF) is introduced in the Czech Republic instead of ecological flow, but the essence is the same. The MRF is the minimum flow of surface water, that still allows general surface water management, provides ecological functions of the watercourse, and allows the possibility of recreational navigation (defined in [5]).

While preparing a new methodological approach, approaches in neighbouring countries such as Germany, Austria, Switzerland, and the United Kingdom were thoroughly examined. In Germany, there is no uniform binding methodology at the federal level. The Water Act defines the minimum water volume below water abstraction in the form of water depth, but specific approaches are addressed at the level of individual federal states. This implies that for 16 states, there are 16 possible approaches. In Bavaria, for example, Equation (1) is used to calculate the MRF:

$$
M R F=\frac{5}{12} Q_{\min }
$$

where

$Q_{\text {min }}$-long-term (1981-2010) average minimum flow $\left[\mathrm{m}^{3} \times \mathrm{s}^{-1}\right]$.

Recently, however, efforts have been made to increase the MRF according to the following Equation (2):

$$
M R F=(0.8-1.2) \times Q_{\min }
$$

In Germany, various modelling tools and methods based on both purely hydrological modelling and habitat change modelling, such as Instream Flow Incremental Methodology (IFIM) (see Methods), are also used in the MRF determination [6]. In Austria, the minimum ecological flow is defined in the Federal Surface Water Law [7]. The minimum ecological flow rate shall be maintained for Austria, provided that a permanent minimum flow rate:

- $\quad$ exceeds the natural minimum daily flow value $\left(Q_{\min }>Q_{\text {min-natural }}\right)$

- represents at least one third of the natural average annual minimum flow

- corresponds to at least half of the natural average annual minimum flow.

In Switzerland, the MRF is defined in the Federal Water Protection Act [8], with the volume derived from size $Q_{95}$ (flow that is reached or exceeded over 347 days a year $\left.\left[\mathrm{m}^{3} \times \mathrm{s}^{-1}\right]\right)$. Its principle is very similar to the current approach in the Czech Republic. However, great administrative powers are left to the individual administrative regions in determining the MRF with regard to prioritizing the social importance of water abstraction or nature protection.

The United Kingdom has significantly addressed the issue of ecological flows in the context of Water Framework Directive implementation $[9,10]$. Within their own methodology, water bodies were classified into eight types, where hydrological, hydromorphological [11], hydrogeological conditions, and fish species occurrence played an important role $[12,13]$. The seasonal nature of the minimum flows was also taken into account when determining flows, ensuring good environmental standards. The minimum flow rate therefore varies according to the type of water body and the occurrence of certain aquatic animals. In the case of the UK, in order to achieve good environmental standards, an important condition appears to be the reduction or complete cessation of water abstraction when $Q_{95}$ flows are achieved or not [9]. In terms of the methodologies used in other countries, the approach approved in the UK can be considered the most comprehensive and played an important role in the design of a new methodology in the Czech Republic.

In accordance with EU documents [2] and the creation of a new methodology, it should be noted that the legislation of the Czech Republic does not recognize the concept of ecological flow, but rather the MRF, which is defined in the Water Act [5]. At present, MRF values in the Czech Republic are still determined according to the 1998 methodological guideline [14]. This document determines the conditions under which the values 
of minimum flows on watercourses are determined. According to the methodological guideline [14], MRF values are determined according to the size of $Q_{97}$ (see Table 1), which is the flow rate with an exceedance probability $97 \%$ (flow that is reached or exceeded on a long-term (1981-2010) average over 355 days a year $\left.\left[\mathrm{m}^{3} \times \mathrm{s}^{-1}\right]\right)$.

Table 1. Guideline values for the MRF of $Q_{97}$.

\begin{tabular}{cc}
\hline$Q_{97} \mathbf{m}^{3} \times \mathbf{s}^{-1}$ & MRF \\
\hline$<0.05 \mathrm{~m}^{3} \times \mathrm{s}^{-1}$ & $Q_{90}$ \\
\hline $0.05-0.5 \mathrm{~m}^{3} \times \mathrm{s}^{-1}$ & $\left(Q_{90}+Q_{97}\right) \times 0.5$ \\
\hline $0.51-5.0 \mathrm{~m}^{3} \times \mathrm{s}^{-1}$ & $Q_{97}$ \\
\hline$>5.0 \mathrm{~m}^{3} \times \mathrm{s}^{-1}$ & $\left(Q_{97}+Q_{99}\right) \times 0.5$ \\
\hline
\end{tabular}

The guideline values given in Table 1 were originally used to set residual flows downstream from the wastewater treatment plants, and specifically to provide the dilution of the cleaned wastewater in the watercourse. In the methodological guideline [14], the values are given as guiding (indicative) values, when the responsible official can adjust the respective values, taking into account local conditions, nature protection, and the type of water abstraction. It is also recommended in the methodological guideline [14] to adjust the MRF value during the year with regard to the hydrological regime of the flow and the needs of aquatic animals. However, the current practice is such that to determine the MRF, the same values from Table 1 are used for all months within the year. Right now, there is no permit for water abstraction or water management within the Czech Republic where the MRF would be adjusted into several values during the year. Overall, it can be stated that the current methodological guideline no longer meets the current hydrological conditions, in terms of climate change, the needs of animal species in watercourses, and the legislative changes made in the Water Act [5].

The new methodology was designed with regard to the following criteria:

- The division of the Czech Republic into several areas where the MRF will be determined in different ways. The areas will take into account the specific hydrological regime, and hydrogeological conditions.

- $\quad$ MRF calculation will take into account the needs of animal species in watercourses.

- Standard hydrological characteristics provided by the Czech Hydrometeorological Institute (CHMI) will be used to calculate the MRF.

- $\quad$ The methodology will determine the methods for calculating the MRF below reservoirs and water works used for water accumulation.

Assuming the above criteria, the following sections describe the procedures and methods used with the aim of developing a new methodology for determining the MRF.

\section{Study Area and Data}

The Czech Republic is a Central European country located in a temperate region with long-term (1981-2010) average annual rainfall of $686 \mathrm{~mm}$ [15]. The spatial distribution of precipitation in the Czech Republic for the reference period 1981-2010 is shown in Figure 1 with the spatial distribution of runoff in surface water bodies in Figure 2 [16]. Both distributions are strongly dependent on altitude and orography whereas high precipitation totals and corresponding runoff heights are associated with mountainous regions located on the borders of the Czech Republic. On the contrary, low precipitation budgets and low runoff heights are located in the lowlands in southeast Moravia and northwest Bohemia which receive approximately $400 \mathrm{~mm}$ on average (the latter is influenced by rain shadow east of the Ore Mountains). Due to specific hydrological conditions associated with the absence of significant transboundary tributaries, the only source of surface water in the Czech Republic is precipitation. Its spatial distribution is significantly influenced by terrain orography, and therefore it was necessary to divide the Czech Republic into at least four 
areas where minimum residual flow (MRF) was determined in different ways (see Methods). Figure 3 shows long-term trends (1941-2017) of the difference between precipitation totals and runoff $(\mathrm{dPR})$, precipitation totals $(\mathrm{P})$, runoff heights $(\mathrm{R})$, and air temperature $(\mathrm{T})$. For the purposes of this study, the observed daily flows for the reference period 1981-2010 of the CHMI gauging station network were used. Data from 334 gauging stations were used and their spatial distribution is shown in Figure 4.

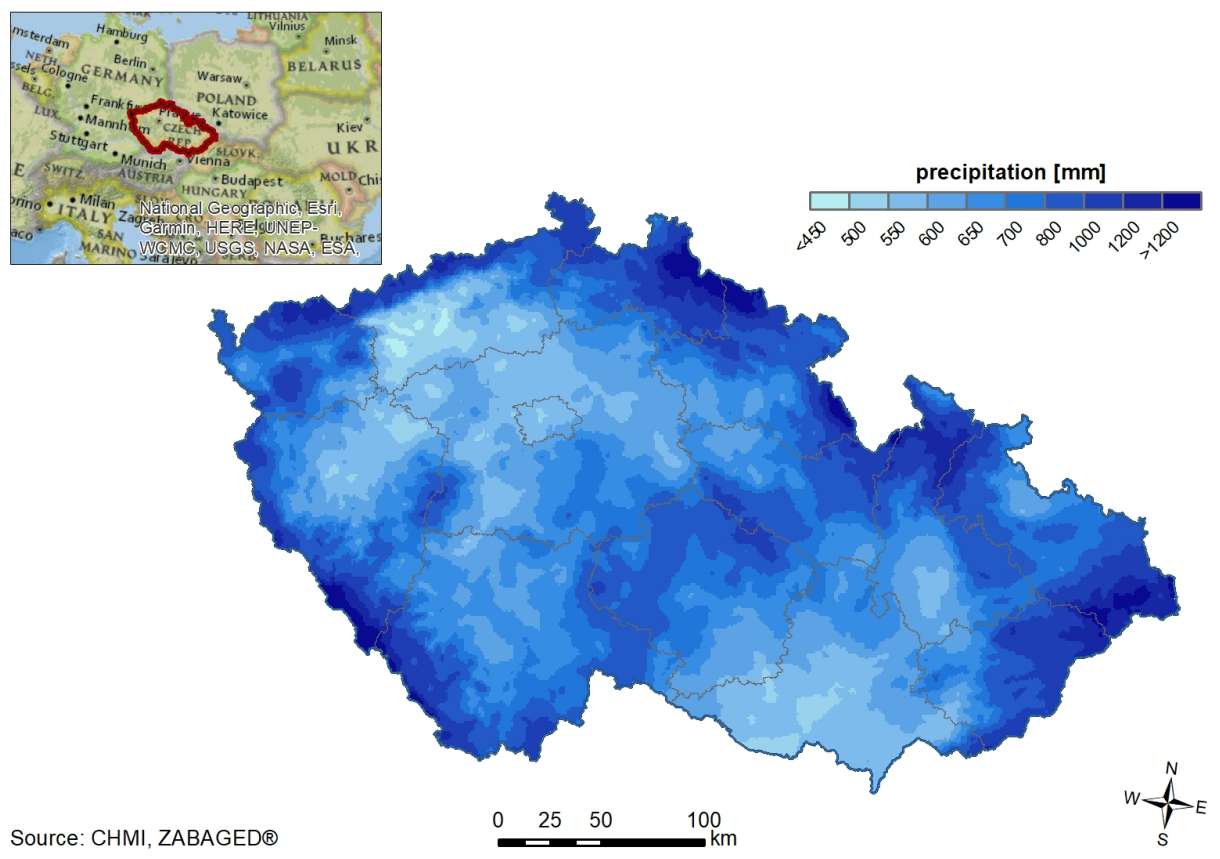

Figure 1. Spatial distribution of average annual precipitation in the Czech Republic for the reference period 1981-2010.

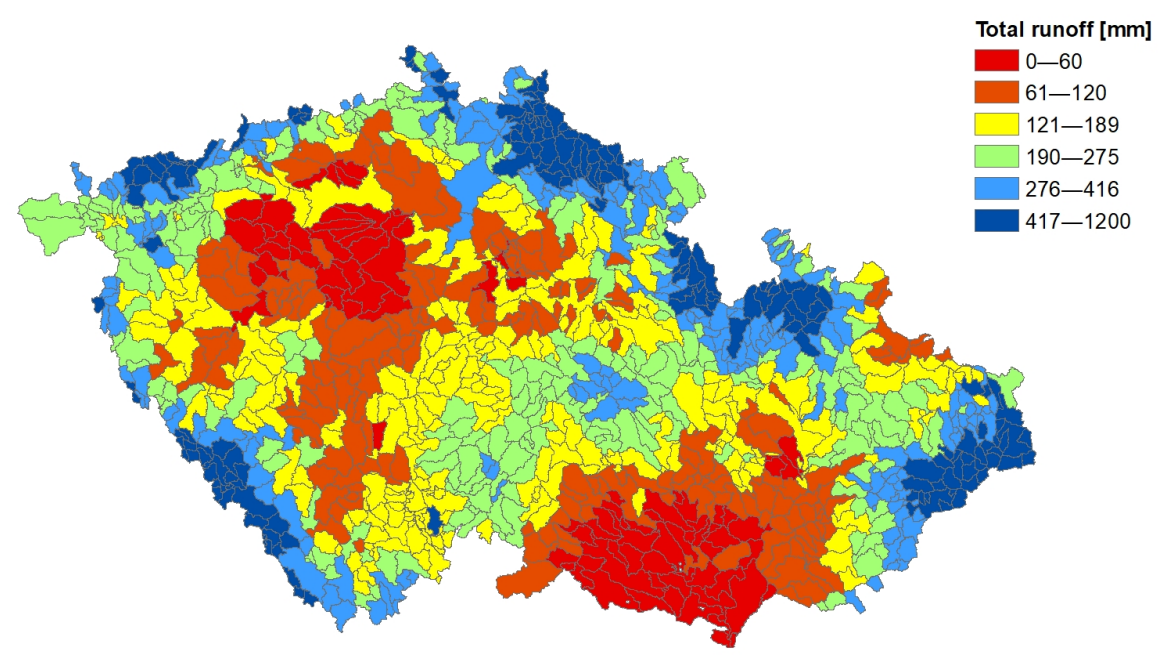

Source: CHMI, ZABAGED®

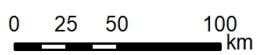

$\hat{p}_{\text {s }}^{N}$

Figure 2. Spatial distribution of average annual runoff height of water surface bodies in the Czech Republic for the reference period 1981-2010. 


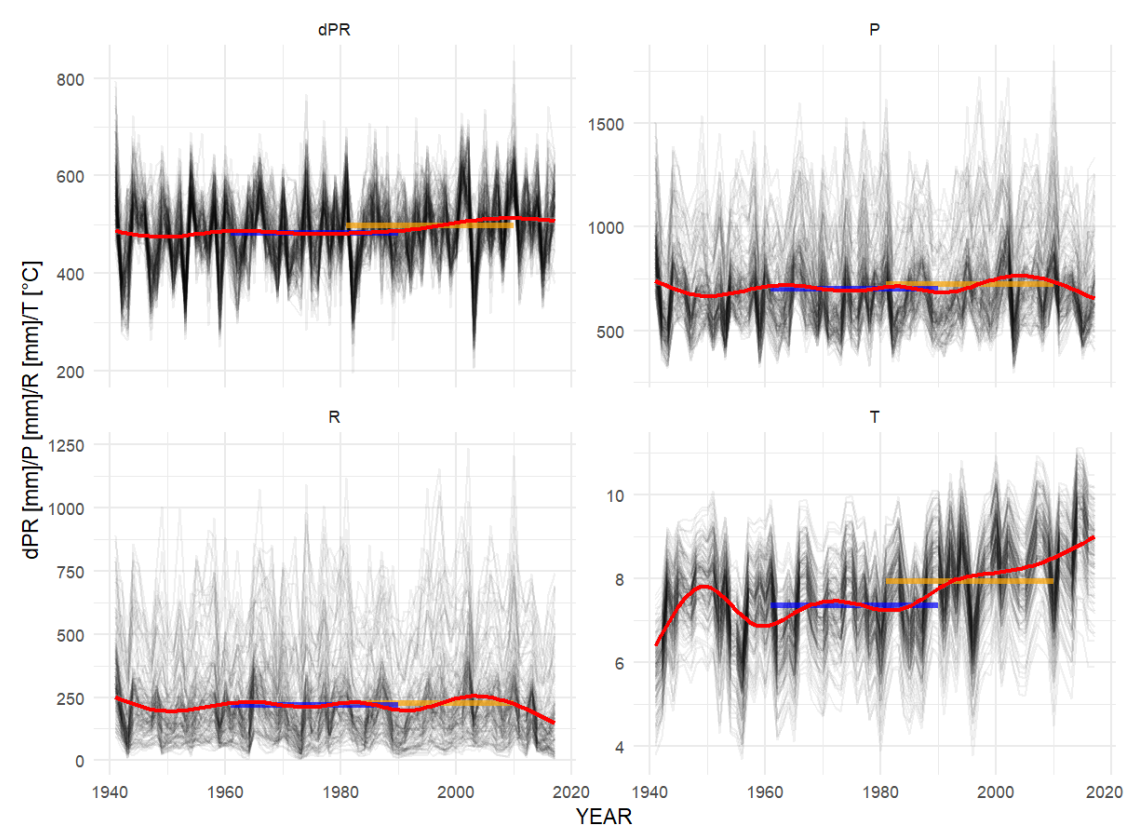

Figure 3. The difference between precipitation totals and runoff $(\mathrm{dPR})$, precipitation totals $(\mathrm{P})$, runoff heights (R), and air temperature (T). Red: local polynomial regression; blue: average for 1961-1990; orange: average for 1981-2010; grey: yearly observation. The data gathered from 334 water gauging stations and 133 meteorological stations.

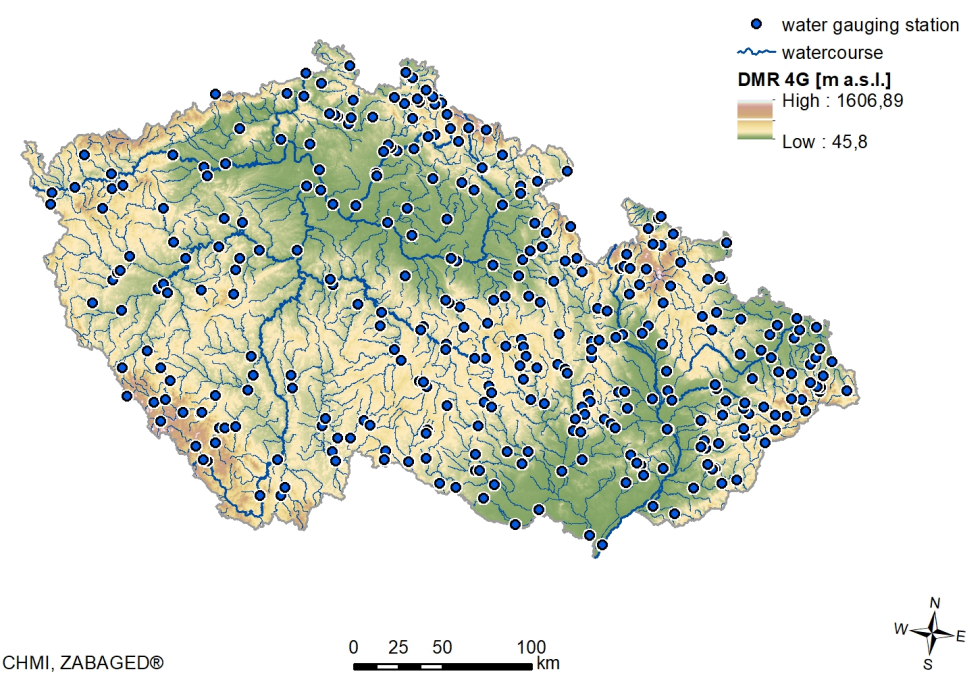

Figure 4. Spatial distribution of gauging stations used to create the methodology.

In addition, long-term (1981-2010) annual average flows and average daily flow with an exceedance probability $99 \%$ were used [17]. The aim was also to assess the possibility of determining the MRF below reservoirs, for which time series of unaffected average monthly flows in profiles below reservoirs were available for the reference period 1981-2010. With regard to the requirement to take into account the needs of animal species in watercourses when calculating the MRF, the results from pilot sites [18-20] where the Instream Flow Incremental Methodology (IFIM) [6] and its model tool Physical Habitat Simulation (PHABSIM) [21] were used in the calculation. The results mainly 
represented the relationship between the so-called Weighted Usable Area (WUA) and flow [6] (see Methods).

\section{Methods}

\subsection{Regional Division of the Czech Republic}

From the available data, areas with different runoff regime (see Table 2 and Figure 5) were defined according to parameter $K_{99}$, which indicates the ratio between the average daily flow with an exceedance probability $99 \%$ and the $Q_{a}$ value (long-term average flow 1981-2010).

$$
K_{99}=\frac{Q_{99}}{Q_{a}}
$$

where

$Q_{99}$-flow that is reached or exceeded on a long-term (1981-2010) average with a probability of $99 \%$ (i.e., is reached or exceeded on a long-term (1981-2010) average over 362 days a year) $\left[\mathrm{m}^{3} \times \mathrm{s}^{-1}\right]$,

$Q_{a}$-long-term (1981-2010) average flow $\left[\mathrm{m}^{3} \times \mathrm{s}^{-1}\right]$.

The thresholds for $K_{99}$ were defined based on the multi-criteria analysis whose objective was to create the least fragmented areas with similar hydrological properties. The analysis was conducted by plotting the values of $K_{99}$ to the map over the layer of hydrogeological districts and the layer of elevation. The borders of given areas were then based on the 4th order basins. Based on this multi criteria analysis, it was decided to divide MRF into four areas with very similar properties as follows:

- Area 1 forms a catchment area of chalk sediments, which represent drainage basins and where the baseflow runoff (i.e. runoff from groundwater reserves) forms a substantial part of total runoff [17], where $K_{99}>0.18$,

- Area 2 consists of mountain catchments with high water content. The balanced nature of the runoff is mainly due to high precipitation. The $K_{99}$ value is usually greater than 0.15 in these areas,

- Area 3 is represented by river catchments formed mainly by crystalline structures, which are found mainly in the submountain areas. Due to the lower altitude, there is an earlier onset of the spring thaw period. Rainfall is also lower here than, for example, in mountain catchments. The $K_{99}$ value in these areas usually ranges from 0.1 to 0.15 , and

- Area 4 is classified as catchments that are characterised by a significantly unbalanced flow regime during the year, where the $K_{99}$ values are less than 0.1 [17].

Table 2. $K_{99}$ values in four defined areas.

\begin{tabular}{cc}
\hline Area According to Regional Division & $\boldsymbol{K}_{\mathbf{9 9}}$ \\
\hline 1 & $>0.18$ \\
\hline 2 & $>0.15$ \\
\hline 3 & $0.1-0.15$ \\
\hline 4 & $<0.1$ \\
\hline
\end{tabular}




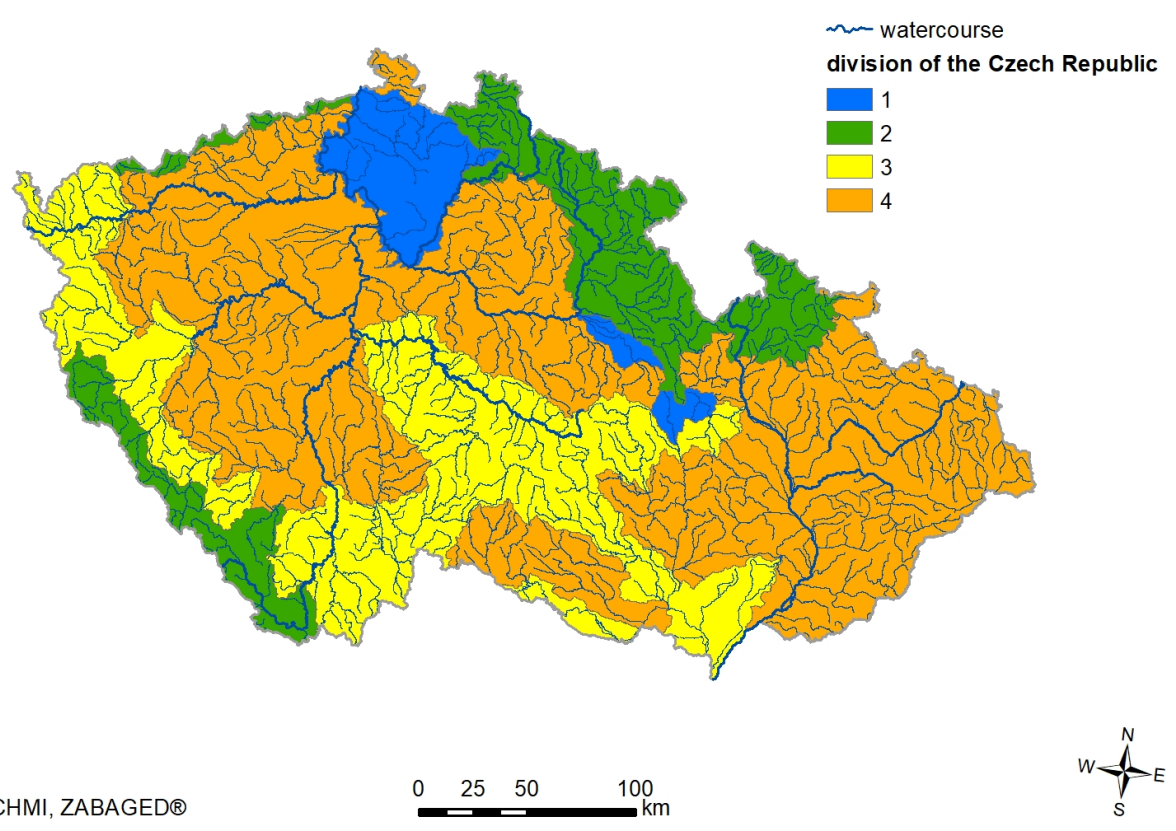

Figure 5. Spatial division of the Czech Republic into individual areas for different MRF calculation based on the coefficient $K_{99}$.

\subsection{Determining the MRF Value}

The next step was the analysis of available data from existing studies aimed at determining the MRF value using IFIM [6] and its model tool PHABSIM [21]. This method was developed by biologists and hydrologists from the United States National Biological Service to find a decision-making tool in optimizing the management of water quantities concerning biological components found in watercourses [22]. IFIM is one of the methods that allows the assessment or design of a minimum flow or flow regime based on biological criteria. Its advantage, compared to other methods, lies in its complexity and relative accuracy. Despite known shortcomings and several comments such as the fact that some parameters are determined subjectively (e.g., number and type of the fish hidings), it provides quantitative and, above all, consistent and comparable results based on which all stakeholders can engage in dialogue. The method is based on the assumption that the production function of the flow for selected target species and their individual life stages can be replaced by the degree of availability of their physical habitat, which is a function of the flow. This degree of availability is defined as the Weighted Usable Area (WUA) [21] based on the relationship in Equation (4) as follows:

$$
W U A_{K}=\sum_{i=1}^{n}\left(\prod_{j} S_{j k}\right) \frac{A_{i}}{L}
$$

where

$K_{K}$-is the given species for which is the WUA calculated (e.g., WUA $A_{\text {Salmotrutta }}$ )

$\Pi$-is the permutation of the $j$ th suitability curve for the $k$ th life stage of the target species,

$S_{j k}$-is the $j$ th suitability curve for the $k$ th life stage of the target species,

$A_{i}$-is a water surface area of the $i$ th part of the riverbed, and

$L$ - is the unit length (usually $1000 \mathrm{~m}$ ). 
The suitability curves represent preferences of habitat or microhabitat of the given life stage of the target species. These preferences are related to watercourse properties such as depth, river flow velocity, river bottom substrate, hidings or temperature. The WUA area for given species changes with the flow (see Figure 6). The optimal minimum flow is always found for given species on the highest point of the curve.

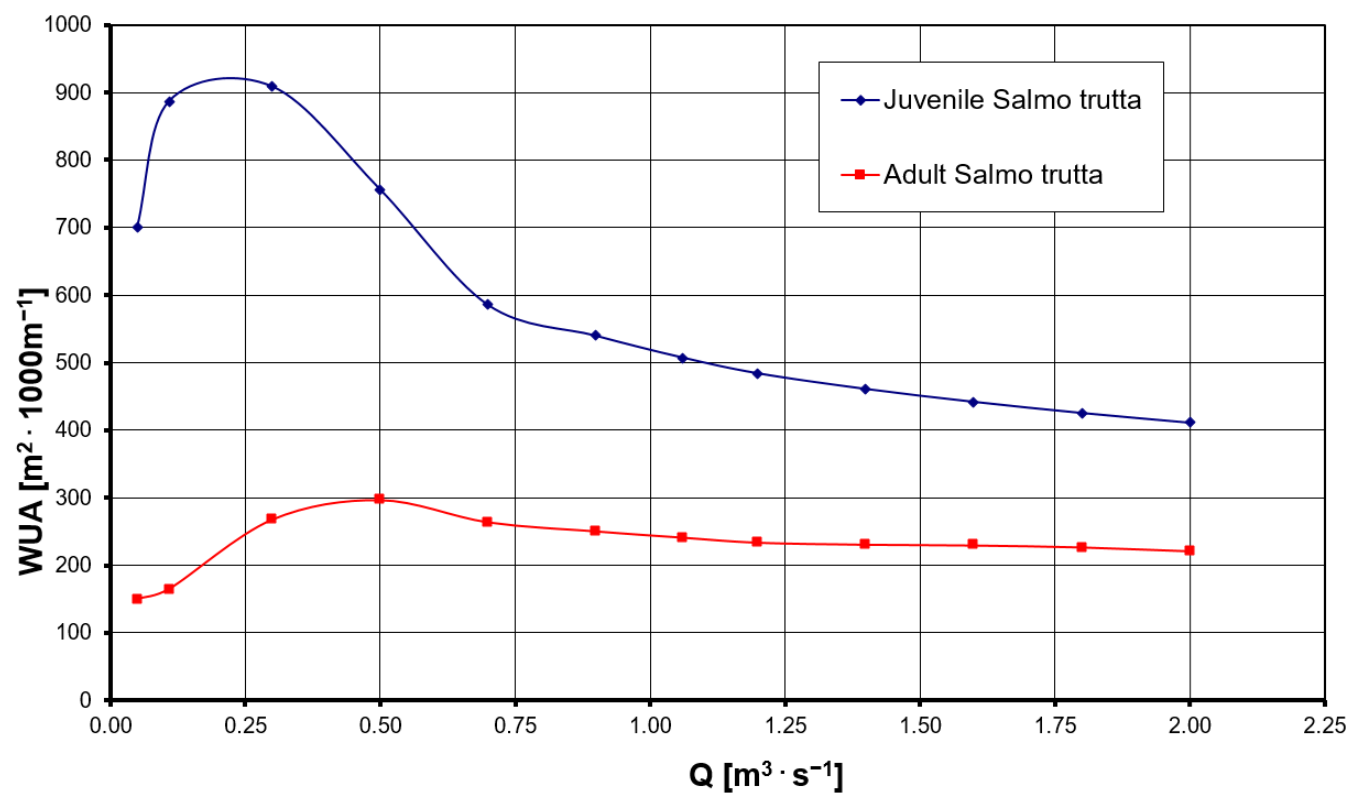

Figure 6. An example of the relationship between Weighted Usable Area (WUA) and flow for Adult Salmo trutta and Juvenile Salmo trutta. The optimal minimum flow is found on the highest point of the curve, $0.24 \mathrm{~m}^{3} \times \mathrm{s}^{-1}$ for juvenile and $0.5 \mathrm{~m}^{3} \times \mathrm{s}^{-1}$ for adult Salmo trutta.

A total of 15 available studies carried out in the Czech Republic were evaluated. The studies were performed mainly on mountain and submountain watercourses in areas 2 and 3 (Figure 5). The results of the studies showed that, according to the relationship between the WUA and flow, the optimal minimum flow for ensuring ecological stability in the watercourse for relevant species (e.g., river trout or Salmo trutta fario) is around $Q_{90}$, which is a flow with an exceedance probability $90 \%$ [23]. The value of the optimal minimum flow was then a crucial parameter for the MRF methodology. One of the requirements of the Nature Conservation Agency of the Czech Republic (NCA CR) is to maintain the MRF at the level of $25-30 \%$ of $Q_{a}$ [17]. For this reason, an evaluation of the dependence of the flow rate with a time of exceeding 330 days per year $\left(Q_{90}\right)$ and the long-term (1981-2010) average flow $Q_{a}$ was performed in individual areas according to Figure 5 . It showed that in area 1 (chalk area with balanced runoff), $Q_{90}$ is $46 \%$ of $Q_{a}$. In areas 2 and 3 (mountain and submountain catchments), $Q_{90}$ is $25-30 \%$ of $Q_{a}$. In area 4 with unbalanced runoff, $Q_{90}$ is $15 \%$ of $Q_{a}$.

The interval for MRF for basins in the Czech Republic was based on the results from pilot sites (where the optimal minimum flow $Q_{90}$ was established), requirements of NCA $\left(0.25 \times Q_{a}\right)$ and the new limit for hydrological drought in the Czech Republic according to CHMI $\left(Q_{97}\right)$. The $Q_{97}$ was established as the lower threshold which is not allowed to be underpassed. Subsequently, an Equation (5) was derived, which is the same for all four areas with a different compensation coefficient $K$ (see Table 3 ). The coefficient $K$ was defined based on data analysis of discharge quantiles (specifically discharges that are reached or exceeded on a long-term (1981-2010) average over 30, 60, 90, 120, 150, $180,210,240,270,300,330,355$, and 364 days a year, i.e. roughly $Q_{8}, Q_{16}, Q_{25}, Q_{33}$. $Q_{41}$, $Q_{50}, Q_{58}, Q_{66}, Q_{74}, Q_{82}, Q_{90}, Q_{97}$, and $Q_{99}$ ) of all 334 gauging stations (see Figure 4) for individual areas (see Figure 5 ). The $K$ value is used for MRF determination in accordance with $0.25 \times Q_{a}$ 


$$
M R F=\left(1-\frac{Q_{97}}{Q_{a}}\right) \times Q_{90} \times K
$$

where

$Q_{97}$ - is the flow that is reached or exceeded on a long-term (1981-2010) average over 355 days a year $\left[\mathrm{m}^{3} \times \mathrm{s}^{-1}\right]$,

$Q_{a}$-is the long-term (1981-2010) average annual flow $\left[\mathrm{m}^{3} \times \mathrm{s}^{-1}\right]$,

$Q_{90}$ - is the flow that is reached or exceeded on a long-term (1981-2010) average over 330 days a year $\left[\mathrm{m}^{3} \times \mathrm{s}^{-1}\right]$,

$K$-is the compensation coefficient (see Table 3).

Table 3. Values of the compensation coefficient $\mathrm{K}$ for individual areas according to Figure 5.

\begin{tabular}{cc}
\hline Area According to Regional Division & $\mathbf{K}$ \\
\hline 1 & 1.2 \\
\hline 2 & 1.1 \\
\hline 3 & 1.05 \\
\hline 4 & 1.07 \\
\hline
\end{tabular}

\subsection{Seasonal MRF Distribution}

To ensure river ecosystem services, it is necessary to consider seasonality. Therefore, the MRF was divided into the so-called main season from May to January, where the MRF calculation is performed according to Equation (5) using the compensation coefficient $K$ according to Table 3, and the secondary season from February to April, which represents the wettest part of the year, and the MRF value is set to $Q_{90}$.

A problem arises in the determination MRF values below water reservoirs and in sections of watercourses where the hydrological regime is strongly influenced by the management of these water reservoirs. The MRF calculation according to Equation (5) does not apply to multi-purpose reservoirs. Due to the great diversity of reservoirs in terms of their size, purpose, and hydrological conditions, the following solution was applied:

1. The MRF below reservoirs is determined on the basis of the water management solution to the water reservoir. The reason for this solution was the clear need to ensure the reliability of storage spaces in reservoirs, especially with regard to ongoing climate change [24],

2. In sections below reservoirs that significantly affect the hydrological regime of the watercourse, the unaffected monthly flows for the reference period 1981-2010 were used for the calculation. Subsequent comparison of affected and unaffected flows showed the possibility of determining empirical values of flows with an exceedance probability $90 \%$ and $97 \%$. However, it was not possible to derive a computational relationship or multiple relationships for all or part of the selected affected sections. Each section would need to be assessed individually and would require a careful assessment of the possible impacts on the biological components of the watercourse.

\section{Results}

The MRF calculation according to Equation 5 and Table 3 was performed for a total of 334 gauging stations. Figure 7a shows the ratio between the MRF and $Q_{a}$ for defined areas (Figure 5). It can be seen from Figure 7 a that for areas 1, 2, and 3, the average MRF is around $0.22-32 \%$ of $Q_{a}$. In area 4 , which is the least balanced in terms of runoff, the $M R F / Q_{a}$ ratio is around $17 \%$. Not all the values of MRF in area 4 meet the requirement of the NCA CR of being between 0.2 and 0.3 . The increase of the coefficient $K$ would increase the MRF globally in the entirety of area 4 and for this reason, an individual assessment was proposed within this area by the given water authority. The new value of the MRF is not 
allowed to be lower than $Q_{97}$. Figure $7 \mathrm{~b}$ shows the ratio between the MRF and $Q_{a}$ when compensation coefficient is reduced to 0.9 (see the following text).

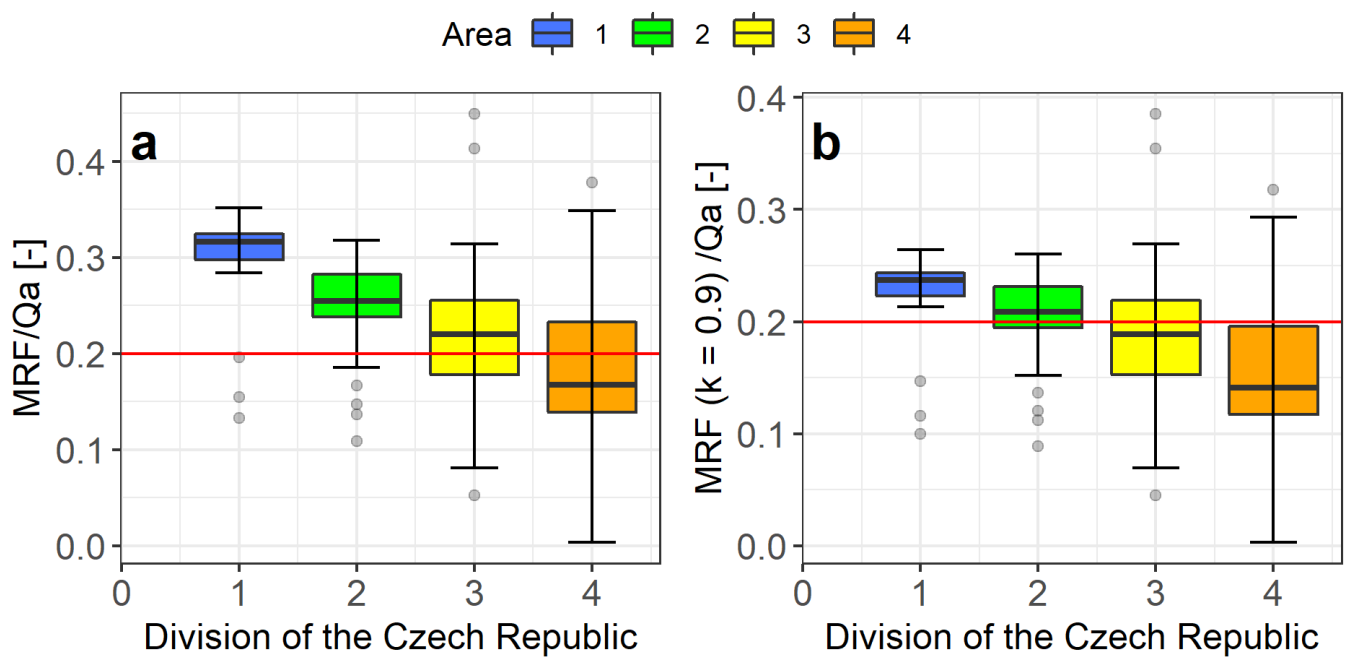

Figure 7. (a) Ratio between MRF and $Q_{a}$. Calculated according to Equation (5), using coefficients from Table 3. (b) Ratio between MRF and $Q_{a}$ assuming that the compensation coefficient is reduced to 0.9 .

Figure 8 shows the application of the MRF calculation for the main season according to Equation (5) and Table 3. It can be seen from Figure 8 that for the majority of the gauging stations, the MRF values are in the required range between $Q_{97}$ and $Q_{90}$. There is a total of 224 gauging stations in the interval $Q_{97}$ and $Q_{90}$. The $Q_{90}$ value was not achieved in 54 of the gauging stations, located mainly in area 4 characterised by unbalanced runoff. The $Q_{90}$ value was exceeded in a total of 36 cases, mainly in areas 1 and 2, which are characterised by balanced runoff. Given that the value of $Q_{97}$ represents the limit for hydrological drought in the Czech Republic, it was decided that in terms of the MRF this flow value should be the lowest limit. Therefore, if the value according to Equation (5) results in a value lower than $Q_{97}$, the MRF will be determined at the level of $Q_{97}$. If the MRF value for the main season is higher than $Q_{90}$ from the calculation according to the Equation (5), the MRF value will be determined at the $Q_{90}$ level.

The water authority may reduce the compensation coefficient $K$ to a value of 0.9 if favourable conditions for ecological functioning of the stream are maintained. The effects of reducing the compensation coefficient to 0.9 are evident (see Figure $7 \mathrm{~b}$ ). Using a compensation coefficient of 0.9 , the average $\mathrm{MRF} / Q_{a}$ ratio in area 1 will be about $25 \%$, in areas 2 and 3 about $20 \%$, and in area 4 about $15 \%$.

By reducing the compensation coefficient to 0.9 , it was also found that the flow $Q_{97}$ was not achieved in 142 out of 334 gauging stations (see the Figure 9). Given that $Q_{97}$ is considered to be the limit for hydrological drought in the Czech Republic, the fact that it is not achieved within the MRF is undesirable, and therefore following relationship applies:

$$
\operatorname{MRF}(0.9)<Q_{97} \Rightarrow M R F=Q_{97}
$$




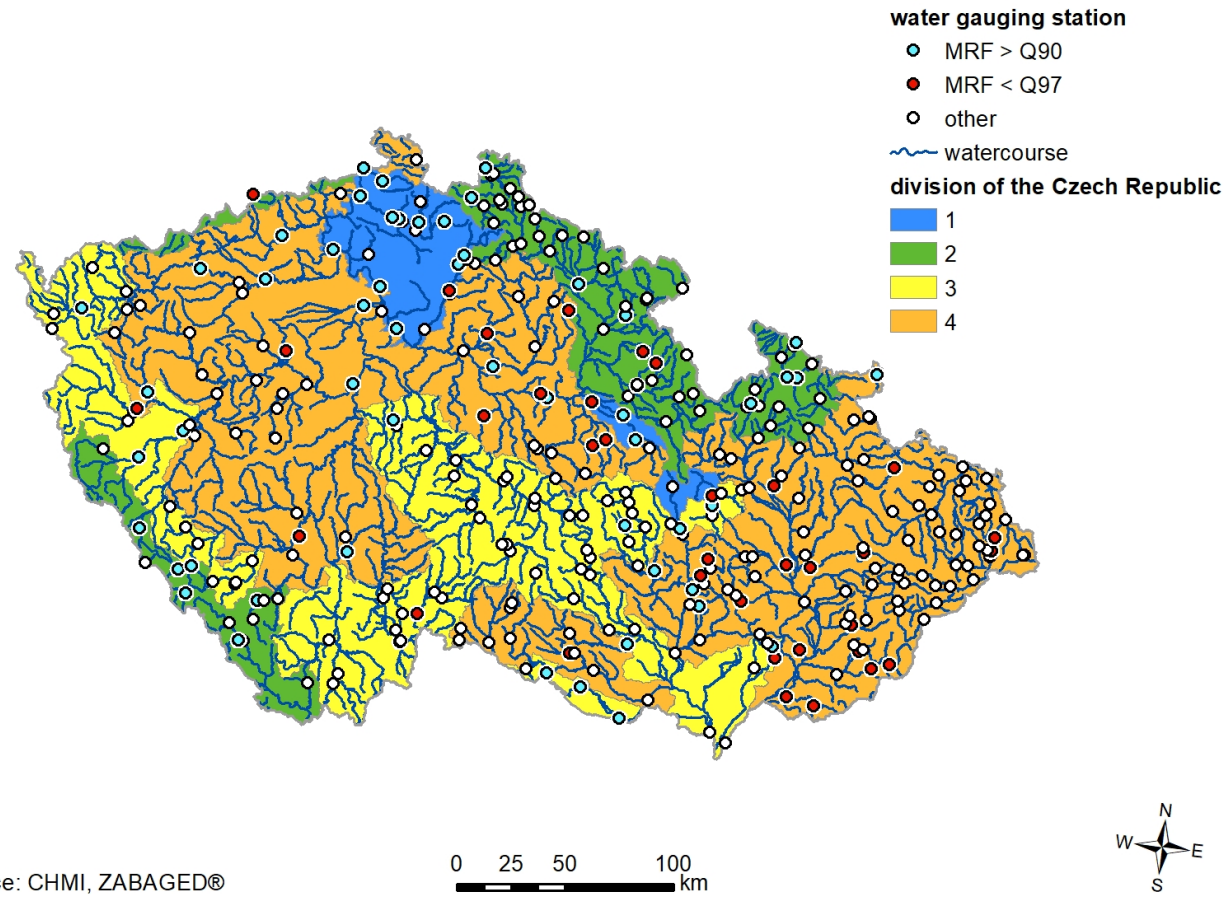

Figure 8. Evaluation of MRF calculation according to Equation (5) and Table 3. Red dots show profiles where the water flow of at least $Q_{97}$ is not achieved - for those, the MRF value is set to $Q_{97}$, and green dost are profiles where the water flow is higher than $Q_{90}$-for those, the MRF value is set to $Q_{90}$.

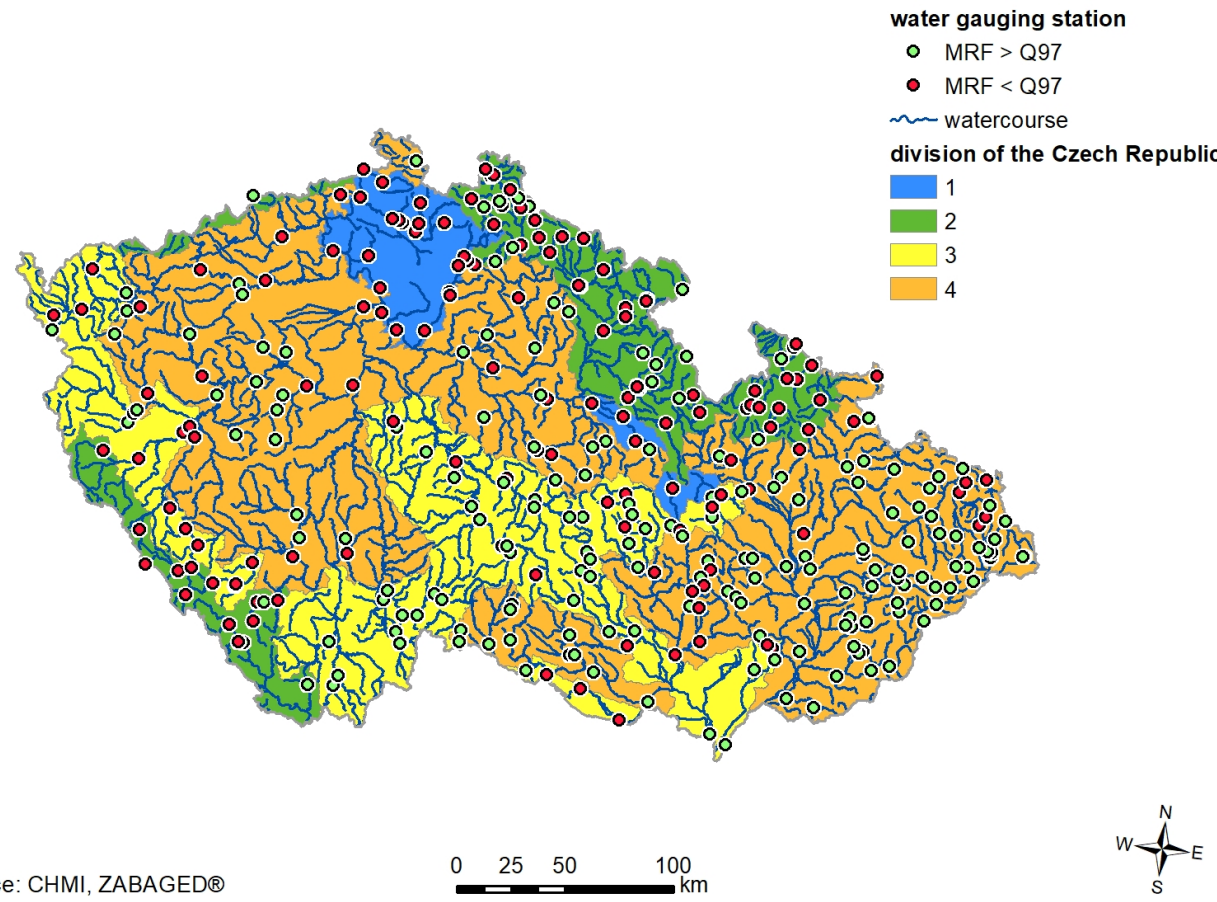

Figure 9. The impact of compensation coefficient (0.9) reduction on MRF values in relation to $Q_{97}$.

The current methodological guidance [14] uses Table 1 for MRF calculation; these are the so-called guideline values. This means that these values are indicative, and it is the responsibility of the relevant water authority whether it will accept them or determine 
other values. Another complication in comparing existing and a newly proposed MRF is the so-called reference period, from which the hydrological characteristics were derived. The period reference 1981-2010 was used to calculate the newly proposed MRF. However, almost a third of the permitted water abstractions have an established MRF from hydrological characteristics for the period 1931-1980. Under these circumstances, a set of typical water abstractions was selected and, in close cooperation with the water authority, a comparison of the new approach and existing permits with the determined MRF was made. The resulting comparison showed that the new approach increases MRF values by an average of $20-30 \%$. This rate of increase in MRF values was assumed; however, the aim of the proposal was to meet EU environmental standards [2,9] and the requirements of the NCA CR. Comparison with currently determined MRF in the Czech Republic is often misleading. However, from the available data, the authors tried to compare the existing [14] and newly proposed approach in the Czech Republic with methodologies abroad.

Figure 10 shows a comparison of the current methodology [14] and the new proposal with the approaches in Bavaria, Germany (existing (DE BAV old) and new proposal (DE BAV new)), the United Kingdom (UK) [9], and Switzerland (CH) [8]. On the horizontal axis are the $Q_{a}$ values, on the vertical axis are the MRF values and their share from $Q_{a}$ in [\%]. The results show a large variance in individual approaches, where the newly proposed MRF calculation for the Czech Republic is closest to the approach in the United Kingdom [9]. The newly proposed calculation for Bavaria, Germany (DE BAV new) is also close to the Czech proposal. The current approach in Bavaria, Germany (DE BAV old) has MRF values of up to $10 \%$ of $Q_{a}$. However, the newly proposed Bavarian approach (DE BAV new) is already bringing significant improvements (see Figure 10). In Switzerland, MRF values range from 10 to $17 \% Q_{a}$.

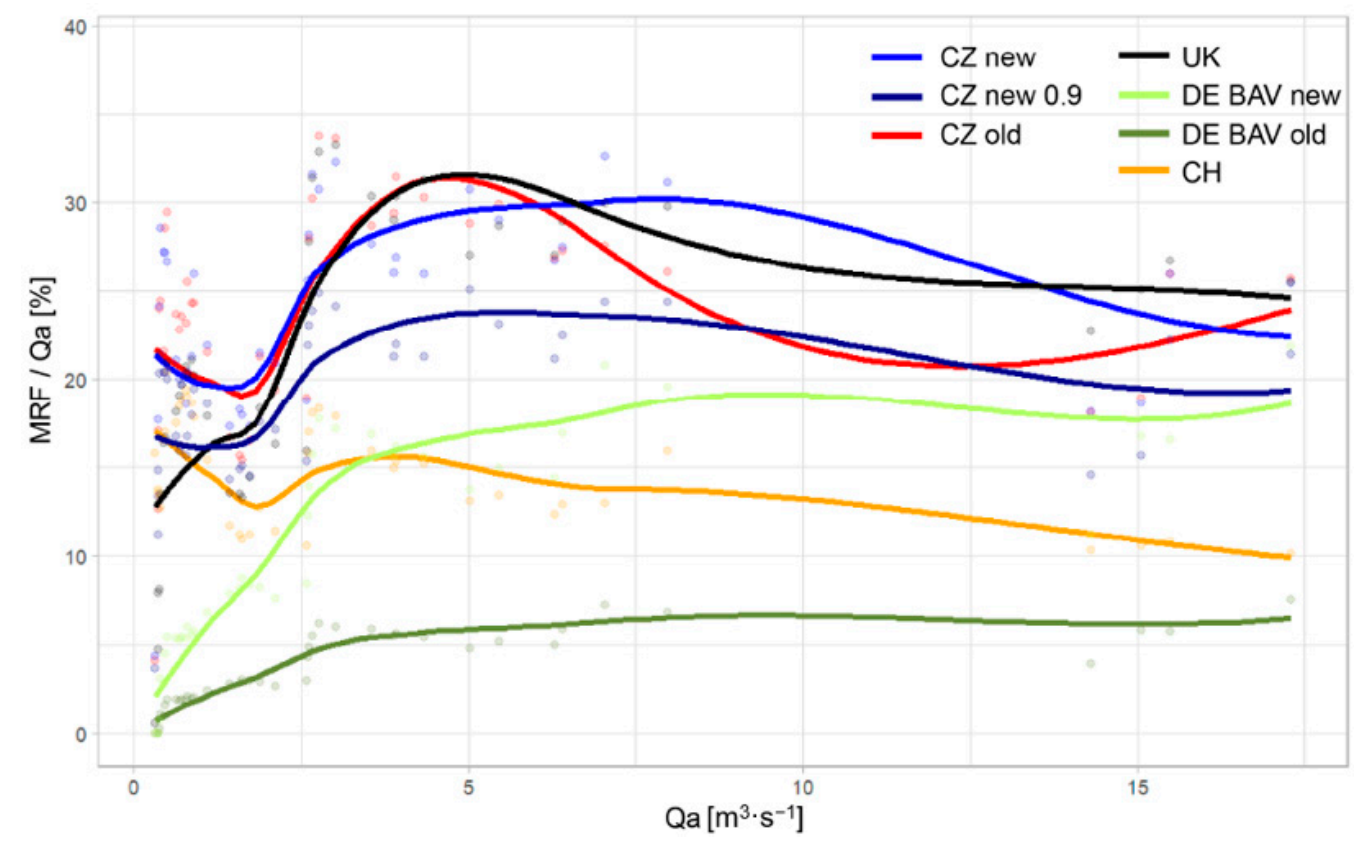

Figure 10. Comparison of MRF values in individual countries in relation to $Q_{a}$. Vertical axis shows a fraction of the MRF from $Q_{a}$ and horizontal axis shows $Q_{a}$. CZ-Czech Republic; CZ new-new proposal, CZ new 0.9-new proposal with compensation coefficient reduced to $0.9, \mathrm{CZ}$ old-existing; UK-United Kingdom; DE-Germany, DE BAV new - new proposal, DE BAV old- existing; and $\mathrm{CH}-$ Switzerland.

\section{Conslusions}

A new methodological approach was developed with the aim of improving ecological standards in watercourses in the Czech Republic, which are no longer met by the original methodological guidance from 1998 [14]. MRF calculation according to guideline values 
(Table 1) without knowledge of biological components needs and without the possibility of changing the MRF during the year is not optimal and does not correspond to current European trends [9]. The new methodological approach will also serve as a basis for the wording of the Regulation of the Government of the Czech Republic. The authors used the results of studies prepared in the Czech Republic using IFIM [6] and its model tool PHABSIM [21]. The results of the studies showed that the ideal flow of the selected biological component is around $Q_{90}$. Based on the requirements of the contracting authority, the Czech Republic was divided into four areas (see Figure 5), where the MRF is determined by the method according to Equation (5) with a different value of the compensation coefficient $K$ (see Table 3). Furthermore, a seasonal distribution of MRF was performed. The MRF was divided into the main season (May to January) and the secondary spring season (February to April). In the main season, the MRF is determined according to Equation (5), and in the spring season, it is determined as the flow value $Q_{90}$. For pragmatic reasons, it was possible to reduce the value of the compensation coefficient to 0.9 (see Figure $7 \mathrm{~b}$ ). The lower limit of MRF values is the value of hydrological drought, which is at the level of $Q_{97}$. In the new methodology, this value is considered the lowest limit. A similar approach is used, for example, in the UK, where water abstraction is restricted or stopped when $Q_{95}$ is reached [9]. The upper limit of the MRF is the $Q_{90}$ flow rate; however, it is the responsibility of water authorities to set a higher flow rate if they find reasons to do so. On important water reservoirs (which do not fall into the category of ponds and small reservoirs), the MRF is determined according to the water management of the reservoir. The requirement to calculate the MRF in sections of watercourses affected by the management of reservoirs from unaffected flows was not accepted by the Ministry of the Environment. The requirement to provide MRF as $0.25 \% Q_{a}$ by the NCA CR was met. The new methodological approach represents an increase of MRF values compared to the current methodology [14], by an average of $20-30 \%$. In some cases, however, there may be a higher increase in MRF values depending on the validity of the derived hydrological characteristics.

In terms of comparison of the methods of determining MRF values in individual European countries, the proposed MRF values in the Czech Republic are rather above average (see the Figure 10). This is due to the hydrological conditions of the Czech Republic, nature conservation needs, and ensuring enough water for further use.

Within the creation of a new methodological approach, it was difficult to find a suitable compromise between the existing and newly proposed MRF values. The MRF and water abstraction are in natural conflict with each other and it is practically impossible to find the optimal solution that will suit both parties. The proposal of this methodology as supporting material for government started a major discussion. While on the side of environmental organizations the new methodology is supported and welcomed (e.g., NCA, and Ministry of the Environment), for the water users (e.g., Ministry of Industry, Agriculture, owners of small hydropower plants) the increase in MRF is causing disapproval and resistance. Negotiations are currently underway, coordinated by the Ministry of the Environment, with the goal of finding a compromise. The proposing method is in principle applicable in other countries. Nevertheless, it requires a certain rearrangement of the input hydrological data to provide compatibility with the methodology of their processing and legislative framework in individual countries. This methodology has been presented at several conferences, and some neighbouring countries (e.g., Slovakia, which has compatible data sets) have showed interest in this methodology.

Author Contributions: Methodology, analysis and computation, writing, project administration and funding, P.B.; analysis and computation, A.V.; regional division of the Czech Republic, M.N.; data evaluation, calculation, J.B.; graphics creation, M.M.; writing, consultation, V.M.; consultation, M.H. All authors have read and agreed to the published version of the manuscript.

Funding: The paper was written as part of the project Analysis of adaptation measures to mitigate the impacts of climate change and urbanization on the water regime in the outer Prague area (CZ.07.1.02/0.0/0.0/16_040/0000380) financed from the Operational Programme Prague - Growth Pole of the Czech Republic. 
Data Availability Statement: The data used for purposes of the study are freely available on the website of the Czech Hydrometeorological Institute according to the law 123/1998. The datasets can be found at https://www.chmi.cz/historicka-data/hydrologie/denni_data/denni-data-dle-z.-123-1 998-Sb.

Conflicts of Interest: The authors declare no conflict of interest. The funders had no role in the design of the study; in the collection, analyses, or interpretation of data; in the writing of the manuscript, or in the decision to publish the results.

Abbreviations
The following abbreviations are used in this manuscript:
$\begin{array}{ll}\text { MRF } & \text { Minimum Residual Flow } \\ \mathrm{P} & \text { Precipitation totals } \\ \mathrm{T} & \text { Temperature } \\ \mathrm{R} & \text { Runoff heights } \\ \mathrm{dPR} & \text { Difference between precipitation totals and runoff } \\ \text { IFIM } & \text { Instream Flow Incremental Methodology } \\ \text { CHMI } & \text { the Czech Hydrometeorological Institute } \\ \text { PHABSIM } & \text { Physical Habitat Simulation } \\ \text { WUA } & \text { Weighted Usable Area } \\ \text { NCA CR } & \text { Nature Conservation Agency of the Czech Republic } \\ \text { WFD } & \text { Water Framework Directive }\end{array}$

\section{References}

1. Blunden, J.; Arndt, D.S. State of the Climate in 2019. Bull. Am. Meteorol. Soc. 2020, 101, S1-S429. [CrossRef]

2. Office for Official Publications of the European Communities. Ecological Flows in the Implementation of the Water Framework Directive-Guidance Document No. 31; Technical Report; European Union: Luxembourg, 2015.

3. WMO. Guidance on Environmental Flows: Integrating E-Flow Science with Fluvial Geomorphology to Maintain Ecosystem Services; Technical Report; World Meteorological Organization (WMO): Geneva, Switzerland, 2019.

4. Office for Official Publications of the European Communities. Ecological Flows in the Implementation of the Water Framework Directive: Compilation of Case Studies Referenced in CIS Guidance Document No. 31; Technical Report; European Union: Luxembourg, 2015.

5. Government of Czech Republic. Water Act-254/2001 Sb; Government of Czech Republic: Prague, Czech Republic, 2010.

6. Bovee, K.D.; Lamb, B.L.; Bartholow, J.M.; Stalnaker, C.B.; Taylor, J. Stream Habitat Analysis Using the Instream Flow Incremental Methodology; Technical Report; Biological Resources Division; Geological Survey (U.S.): Fort Collins, Colorado, 1998.

7. Federal Minister for Agriculture and Forestry, Environment and Water Management. Federal Law Gazette for the Republic of Austria: Water Management on the Definition of the Ecological Status of Surface Waters; Federal Minister for Agriculture and Forestry, Environment and Water Management: Vienna, Austria, 2010.

8. The Federal Assembly of the Swiss Confederation. Federal Act on the Protection of Waters-Waters Protection Act, 814.20; The Federal Assembly of the Swiss Confederation: Geneva, Switzerland, 1991.

9. Acreman, M.; Dunbar, M.; Hannaford, J.; Mountford, O.; Wood, P.; Holmes, N.; Cowx, I.; Noble, R.; Extence, C.; Aldrick, J.; et al. Developing environmental standards for abstractions from UK rivers to implement the EU Water Framework Directive/Développement de standards environnementaux sur les prélèvements d'eau en rivière au Royaume Uni pour la mise en œuvre de la directive cadre sur l'eau de l’Union Européenne. Hydrol. Sci. J. 2008, 53, 1105-1120. [CrossRef]

10. Petts, G.; Crawford, C.; Clarke, R.; Authority, N.R. Determination of Minimum Flows; R \& D Note, National Rivers Authority; University of Birmingham: Birmingham, UK, 1996.

11. Booker, D.J.; Acreman, M.C. Generalisation of physical habitat-discharge relationships. Hydrol. Earth Syst. Sci. 2007, 11, 141-157. [CrossRef]

12. Cowx, I.; Pitts, C.; Smith, K. Factors Influencing Coarse Fish Populations in Rivers; R and D Publication-Environment Agency: Bristol, $\mathrm{UK}, 2001$.

13. Cowx, I.; Noble, R.; Nunn, A.; Harvey, J.; Welcomme, R.; Halls, A. Flow and Level Criteria for Coarse Fish and Conservation Species; Environment Agency Science Report SC020112/SR; Environment Agency: Bristol, UK, 2004.

14. Ministry of Environment of the Czech Republic. Methodical Instruction of the Department of Water Protection of the Ministry of the Environment to Determine the Values of Minimum Residual Flows in Watercourses; Ministry of Environment of the Czech Republic: Prague, Czech Republic, 1998.

15. Tolasz, R.; Čekal, R.; Škáchová, H.; Vlasáková, L. The year 2019 in Czechia. Meteorol. Bull. 2020, 73, 3-13.

16. Vizina, A.; Hanel, M.; Trnka, M.; Daňhelka, J.; Gregorieová, I.; Heřmanovský, M. HAMR: Online drought management system-operational management during a dry episode. Water Manag. Tech. Econ. Inf. J. (VTEI J.) 2018, 60, $22-28$. 
17. Balvín, P.; Vizina, A. Determination of minimum residual flow values in the Czech Republic. Water Manag. Tech. Econ. Inf. J. (VTEI J.) 2018, 60, 8-13.

18. Jiřinec, P.; Slavík, O.; Mattas, D. Stanovení minimálních ekologických průtoků na řece Vydře pro návrh manipulařního řádu odběru Rechle. In Revitalizace Vodních Ekosystémů, Správa NP a CHKO Šumava: Srní, Czech Republic, 1999; pp. 21-32.

19. VÚV TGM, V.V.I. Stanovení Minimálních Ekologických Průtoků na Přísečnici a Černé Vodě: Výzkumná Zpráva; VÚV TGM, V.V.I.: Prague, Czech Republic, 2002.

20. VÚV TGM, V.V.I. Stanovení Minimálních Ekologických Průtoků na Svatavě: Výzkumná Zpráva; VÚV TGM, V.V.I.: Prague, Czech Republic, 2003.

21. Milhous, R.T.; Updike, M.A.; Schneider, D.M. Physical Habitat Simulation System Reference Manual: Version II; Technical Report; US Fish and Wildlife Service: Washington, DC, USA, 1989.

22. Stalnaker, C.B.; Arnette, J.L. Methodologies for the Determination of Stream Resource Flow Requirements: An Assessment; Utah State University: Logan, UT, USA, 1976.

23. Mrkvičková, M.; Balvín, P. Proposal for minimum residual flow setting. Water Manag. Tech. Econ. Inf. J. (VTEI J.) 2013, 55, 12-16.

24. Nacházel, K.; Fošumpaur, P. Possibility theory in hydrology and water management. J. Hydrol. Hydromech. 2010, 58, 73-87. [CrossRef] 